\title{
Cardiopulmonary Resuscitation in Prone Position
}

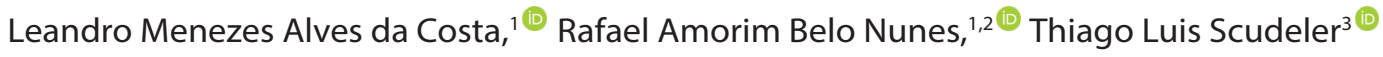 \\ Hospital Alemão Oswaldo Cruz, ${ }^{1}$ de São Paulo, SP - Brazil \\ Hospital das Clínicas da Faculdade de Medicina da Universidade de São Paulo, ${ }^{2}$ São Paulo, SP - Brazil \\ Instituto do Coração (InCor), ${ }^{3}$ São Paulo, SP - Brazil
}

\begin{abstract}
Mechanical ventilation in prone position is an alternative strategy for patients with acute respiratory discomfort syndrome (ARDS) to improve oxygenation in situations when traditional ventilation modalities have failed. However, due to the significant increase in ARDS cases during the SARS-CoV-2 pandemic and the experimental therapeutic use of potentially arrhythmogenic drugs, cardiopulmonary resuscitation in this unusual position could be needed. Therefore, we will review the available scientific evidence of cardiopulmonary resuscitation in prone position.
\end{abstract}

\section{Relevance}

The current Coronavirus Disease 2019 (COVID-19) pandemic resulting from SARS-CoV-2 infection requires the highest level of medical response from health care services worldwide. Pneumonia is the most common comorbid condition, with acute respiratory discomfort syndrome (ARDS) as the main complication. Current studies have demonstrated that 20 to $41 \%$ of patients with COVID-19 develop ARDS, and 12.3\% of these patients require mechanical ventilation. ${ }^{1,2}$ For patients where predefined ventilation parameters are not met and patients with refractory hypoxemia, prone-position ventilation (PPV) has been suggested as a valuable alternative. ${ }^{3,4}$

PPV alters the mechanical and physiological structure of the gaseous exchange, creating a more homogenous ventilation system, decreasing ventral alveolar extension, and diminishing dorsal alveolar collapse. ${ }^{5}$ This can

\section{Keywords}

Cardiopulmonary Ressuscitation, Electric Countershock/ methods; respiration, Artificial/methods; Pronation. effectively reduce the difference between transpulmonary dorsal and ventral pressures. In addition, PPV reduces pulmonary compression and improves corporeal perfusion. ${ }^{6,7}$ Prone ventilation should be initiated in the first 36 hours of mechanical ventilation and ideally be maintained for 12 to 16 hours. ${ }^{4}$

During this period of treatment, the patient may become vulnerable to emergency situations, with cardiac arrest as the diagnosis with the worst prognosis. Moreover, the current use of experimental drugs may increase the occurrence of malignant arrhythmia. The combination of hydroxychloroquine and azithromycin predisposes to QT interval prolongation on electrocardiogram. ${ }^{8}$ This could consequently increase the potential risk for dangerous ventricular arrhythmias, requiring specific technical knowledge in the performance of synchronized electric cardioversion or cardiac defibrillation while the patient is in prone position. Additionally, an assistance team with little experience in cardiopulmonary resuscitation while in prone position represents a particularly challenging complication, especially considering the adoption of respiratory isolation and use of personal protective equipment.

\section{Objective}

To review the scientific evidence related about prone cardiopulmonary resuscitation.

\section{Background}

First described by Dr. McNeil in 1989, ${ }^{9}$ the first case of cardiopulmonary resuscitation (CPR) in prone position claimed success in practice by Dr. Sun and colleagues in 1992. ${ }^{10}$ While still not adopted as a routine practice, this technique meets the prerequisite ideas of resuscitation, guaranteeing adequate ventilation associated with thoracic compressions, requiring only simple training. 
Several small studies have shown that dorsal compressions cause an increase in arterial pressure in comparison to conventional compressions. A pilot study in which six patients received 15 minutes of CPR in conventional position, followed by 15 minutes of CPR in prone position, resulted in a systolic arterial pressure increase from $48 \mathrm{mmHg}$ to $72 \mathrm{mmHg}$ with prone-position CPR. ${ }^{11} \mathrm{~A}$ separate study compared the levels of systolic and diastolic arterial pressure (SAP, DAP) with invasive monitoring in 11 cadavers and found higher levels of SAP and DAP in patients who received CPR in prone position $(79 \pm 20 / 17 \pm 10 \mathrm{mmHg}$ in the experimental prone group, compared to $55 \pm 20 / 13 \pm 7 \mathrm{mmHg}$ in the conventional group, $\mathrm{p}=0.028) .{ }^{12}$

Mazer et al. ${ }^{11}$ suggested a possible explanation for the increased efficiency of prone-position CPR. ${ }^{11}$ According to their study, external cardiac compressions in prone positions generate a greater force due to the costovertebral articulations and their increased rigidity. This allows greater variation in intra-thoracic pressure and more effective direct cardiac compression, providing better circulatory effects. Moreover, the prone position provides high level of patency in airways, and the increased intra-thoracic pressure variation favors lung ventilation.

The American Heart Association included CPR in prone position in their recommendations for advanced treatment in life support in 2010. ${ }^{13}$ These recommendations are applied to patients unable to move spontaneously, making the shifting to the supine position impossible, especially patients who underwent dorsal surgical procedures with vascular resection, neurosurgeries, or treatments to the spinal vertebrae. ${ }^{14-19}$ These recommendations have remained unchanged in modern revisions since 2015. ${ }^{20}$

\section{Cardiac compressions}

Prone-position CPR can be performed with one or two hands and with or without external counterpressure. ${ }^{21-23}$ For thoracic compressions, place the hypothenar region of the hand above the patient's thoracic vertebrae, and the other hand over the first, lacing them together. A study by Kwon and colleagues used computerized tomographic images to demonstrate that the best position for thoracic compressions lies 0-2 vertebral segments below the inferior angle of the scapula (T8-T9). Typically, this region provides more direct access to the larger left ventricle in the transversal area (Figure 1). ${ }^{24}$

Prone-position CPR should be similar to conventional CPR with compressions between 5 and $6 \mathrm{~cm}$, with frequency between 100 to 120 compressions per minute,

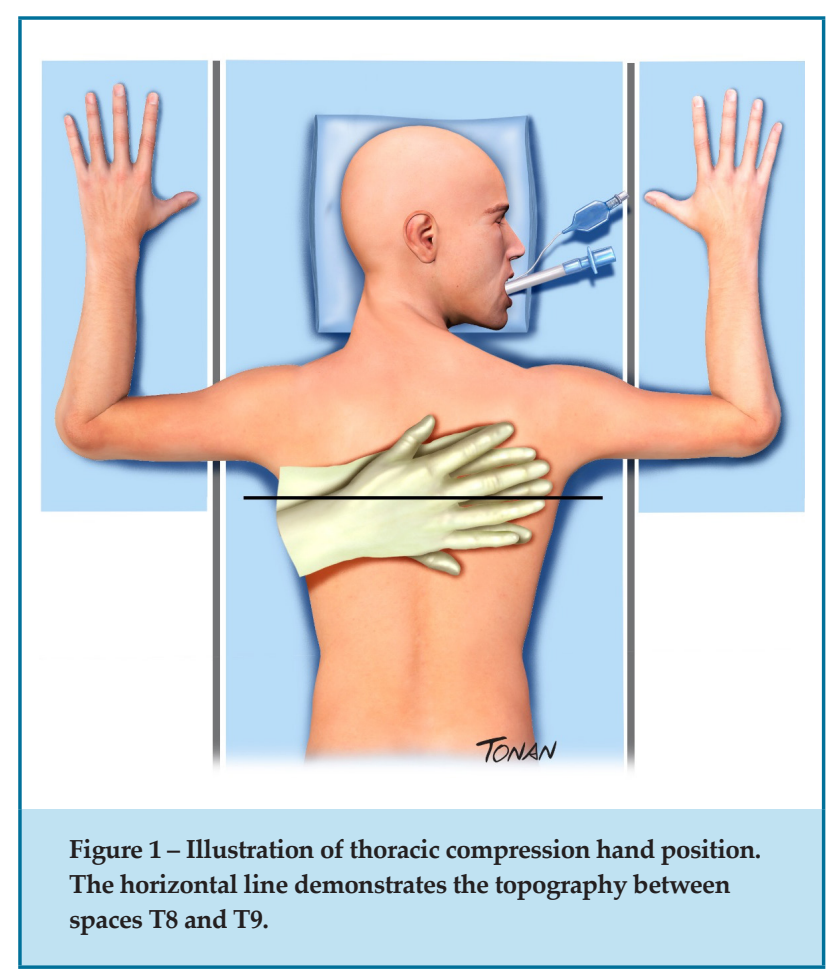

allowing the thorax to return to the original position. A capnography allows for an effective measurement of the exhaled $\mathrm{CO}_{2}$ to evaluate the effectiveness of the treatment. In 2001, Brown et al., ${ }^{24}$ published the first systematic review article about prone-position CPR. The authors identified 22 intubated patients who received prone-position CPR, 10 of whom received hospital discharge following treatment. ${ }^{25}$

\section{Defibrillation}

Defibrillation in prone position is another important aspect in prone-position CPR. It can be performed in the posterolateral-prone-position (one of the blades is positioned in the middle axillary line on the left, at the fifth intercostal space and the other blade is positioned in the distal portion of the scapula on the right) or bilateral axillary. ${ }^{26,27}$ (Figures 2 and 3)

\section{Conclusion}

Cardiopulmonary resuscitation in prone position proves to be a viable alternative in situations where it is not possible to return the patient to the traditional supine position, since it provides immediate initiation of chest compressions, reduces the risk of displacement of tubes and catheters, and contamination of the health professionals involved in patients' care. 


\section{Acknowledgements}

We thank the designer Rodrigo R. Tonan, for his willingness, and excellence of the work performed.

\section{Potential Conflict of Interest}

No potential conflict of interest relevant to this article was reported.

\section{Sources of Funding}

There were no external funding sources for this study.

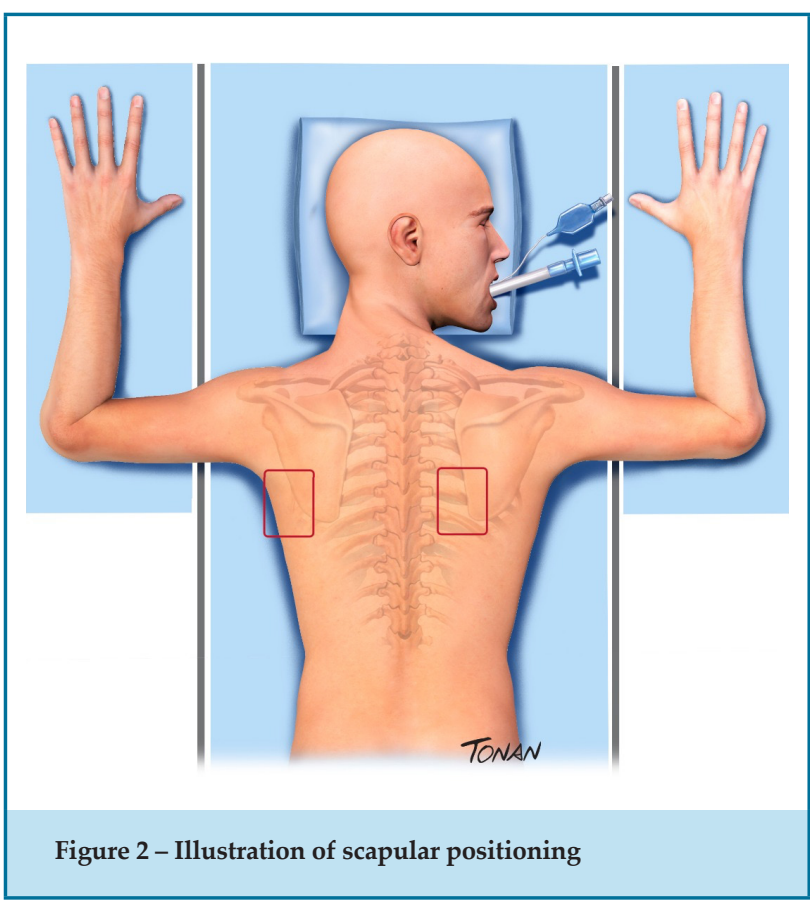

\section{References}

1. Wang D, Hu B, Hu C, Zhu F, Liu X, Zhang J, et al. Clinical characteristics of 138 hospitalized patients with 2019 novel coronavirus-infected pneumonia in Wuhan, China. JAMA. 2020;323(11):1061-9.

2. Wu C, Chen X, Cai Y, Xia J, Zhou X, Xu S, et al. Risk factors associated with acute respiratory distress syndrome and death in patients with coronavirus disease 2019 pneumonia in Wuhan, China. JAMA Intern Med. 2020;180(7):1-11.

3. Gattinoni L, Tognoni G, Pesenti A, Tacconi P, Mascheroni D, Labarta V, et al. Effect of prone positioning on the survival of patients with acute respiratory failure. N Engl J Med. 2001;345(8):568-73.

4. Alhazzani W, Møller MH, Arabi YM, Loeb M, Gong MN, Fan E, et al Surviving sepsis campaign: guidelines on the management of critically ill adults with coronavirus disease 2019 (COVID-19). Crit Care Med. 2020;48(6):e440-69.

5. Cornejo RA, Diaz JC, Tobar EA, Bruhn AR, Ramos CA, González RA, et al. Effects of prone positioning on lung protection in patients with acute

\section{Study Association}

This study is not associated with any thesis or dissertation work.

\section{Author Contributions}

Conception and design of the research: Leandro MA Costa, Thiago L Scudeler. Acquisition of data: Leandro MA Costa, Thiago L Scudeler. Analysis and interpretation of the data: Leandro MA Costa, Thiago L Scudeler. Writing of the manuscript: Leandro MA Costa, Thiago L Scudeler. Critical revision of the manuscript for intellectual content: Leandro MA Costa, Thiago L Scudeler.

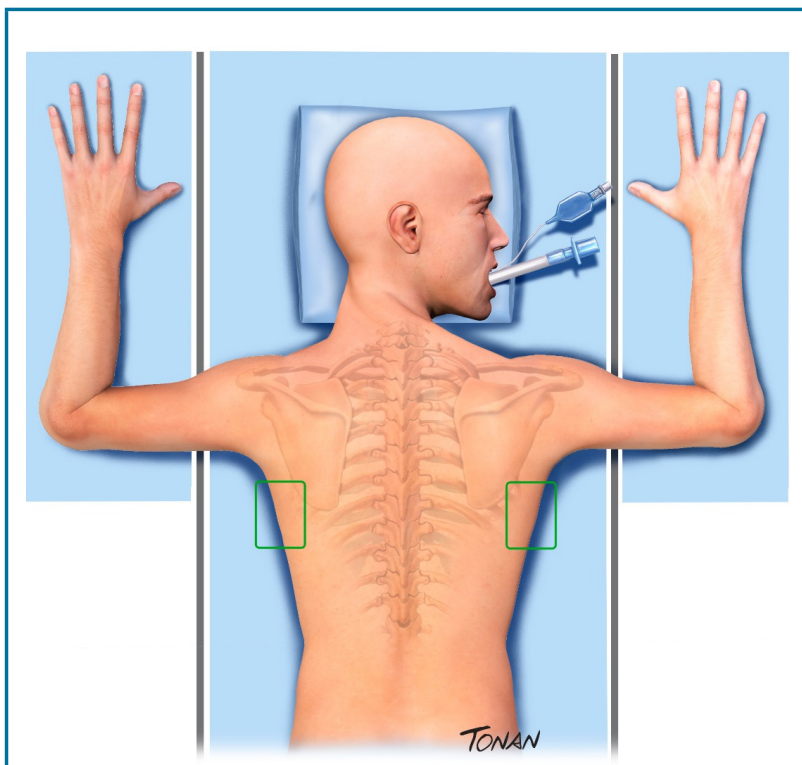

Figure 3 - Illustration of biaxial positioning

6. Albert RK, Hubmayr RD. The prone position eliminates compression of the lungs by the heart. Am J Respir Crit Care Med. 2000;161(5):1660-5.

7. Nyren S, Radell P, Lindahl SG, Mure M, Petersson J, Larsson SA, et al. Lung ventilation and perfusion in prone and supine postures with reference to anesthetized and mechanically ventilated healthy volunteers. Anesthesiology. 2010;112(3):682-7.

8. Simpson T, Salazar J, Vittinghoff E, Probert J, Iwahashi A, Olgin JE, et al. Association of QT prolonging medications with risk of autopsy causes of sudden death. JAMA Int Med. 2020;180(5):1-9.

9. McNeil EL. Prone CPR aboard aircraft (McNeil method) J Emerg Nurs. 1994;20:446.

10. Sun WZ, Huang FY, Kung KL, Fan SZ, Chen TL. Successful cardiopulmonary resuscitation of two patients in the prone position using reversed precordial compression. Anesthesiology. 1992;77(1):202-4. 
11. Mazer SP, Weisfeldt M, Bai D, Cardinale C, Arora R, Ma C, et al. Reverse CPR: a pilot study of CPR in the prone position. Resuscitation. 2003;57(3):279-85.

12. Wei J, Tung D, Sue SH, Wu SV, Chuang YC, Chang CY. Cardiopulmonary resuscitation in prone position: a simplified method for outpatients. J Chin Med Assoc. 2006;69(5):202-6.

13. Lowenthal A, Lehmann-Meurice C, Otteni JC. Efficacy of external cardiac massage in a patient in the prone position. Ann Fr Anesth Reanim. 1993;12(6):587-9.

14. Tobias JD, Mencio GA, Atwood R, Gurwitz GS. Intra-operative cardiopulmonary resuscitation in the prone position. J Pediatr Surg. 1994;29(12):1537-8.

15. Kelleher A, Mackersie A. Cardiac arrest and resuscitation of a 6-month old achondroplastic baby undergoing neurosurgery in the prone position. Anaesthesia. 1995;50(4):348-50.

16. DeQuin PF, Hazouard E, Legras A, Lanotte R, Perrotin D Cardiopulmonary resuscitation in the prone position: Kouwenhoven revisited. Intensive Care Med. 1996;22(11):1272-82.

17. Brown J, Rogers J, Soar J. Cardiac arrest during surgery and ventilation in the prone position: a case report and systematic review. Resuscitation. 2001;50(2):233-8.

18. Taylor JCL, Buchanan CCR, Rumball MJ. Cardiac arrest during craniotomy in prone position. Trends Anaesth Cri Care. 2013;3(4):224-6.

19. Brooks SC, Anderson ML, Bruder E, Daya MR, Gaffney A, Otto CW, et al. Part 6: Alternative techniques and ancillary devices for cardiopulmonary resuscitation: 2015 American Heart Association Guidelines update for cardiopulmonary resuscitation and emergency cardiovascular care. Circulation. 2015;132(18 Suppl 2):S436-43
20. Sun W, Huang F, Kung K, Fan S, Chen T. Successful cardiopulmonary resuscitation of two patients in the prone position using reversed precordial compression. Anesthesiology. 1992;77(1):202-4.

21. Dequin P-F, Hazouard E, Legras A, Lanotte R, Perrotin D Cardiopulmonary resuscitation in the prone position: kouwenhoven revisited. Intensive Care Med. 1996;22(11):1272.

22. Tobias JD, Mencio GA, Atwood R, Gurwitz GS. Intraoperative cardiopulmonary resuscitation in the prone position. J Paediatr Surg. 1994;29(12):1537-8

23. Kwon MJ, Kim EH, Song IK, Lee JH, Kim HS, Kim JT. Optimizing prone cardiopulmonary resuscitation: identifying the vertebral level correlating with the largest left ventricle cross-sectional area via computed tomography scan. Anesth Analg. 2017;124(2):520-3.

24. Brown J, Roger J, Soar J. Cardiac arrest during surgery and ventilation in the prone position: a case report and systematic review. Resuscitation. 2001;50(2):233-8

25. Miranda CC, Newton MC. Successful defibrillation in the prone position. Br J Anaesth. 2001;87(6):937-8.

26. Link MS, Atkins DL, Passman RS, Halperin HR, Samson RA, White RD, et al. Part 6: Electrical therapies: automated external defibrillators, defibrillation, cardioversion, and pacing.. Circulation. 2010;122(18 Suppl 3):S706-19.

27. Cave DM, Gazmuri RJ, Otto CW, Nadkarni VM, Cheng A, Brooks SC, et al. Part 7: CPR techniques and devices: 2010 American Heart Association Guidelines for Cardiopulmonary Resuscitation and Emergency Cardiovascular Care. Circulation. 2010;122(18 Suppl 3):S720-8. 